DIGITALCOMMONS

—@WAYNESTATE —
Michigan Journal of Counseling:

Research, Theory and Practice

Volume 37 | Issue 1

Article 2

$3-1-2010$

\title{
The Development of an Emotional Response to Writing Measure: the Affective Cognition Writing Survey
}

\author{
Ronald G. Fischer \\ Minot State University \\ Jerome M. Fischer \\ University of Texas Pan-American, jmfischer@utpa.edu \\ Sachin Jain \\ University of Idaho
}

Follow this and additional works at: https://digitalcommons.wayne.edu/mijoc

\section{Recommended Citation}

Fischer, R. G., Fischer, J. M., \& Jain, S. (2010). The Development of an Emotional Response to Writing Measure: the Affective Cognition Writing Survey, Michigan Journal of Counseling, 37(1), 1-15. doi:10.22237/mijoc/1267401660

This Article is brought to you for free and open access by the Open Access Journals at DigitalCommons@WayneState. It has been accepted for inclusion in Michigan Journal of Counseling: Research, Theory and Practice by an authorized editor of DigitalCommons@WayneState. 


\section{The Development of an} Emotional Response to Writing Measure: the Affective Cognition Writing Survey

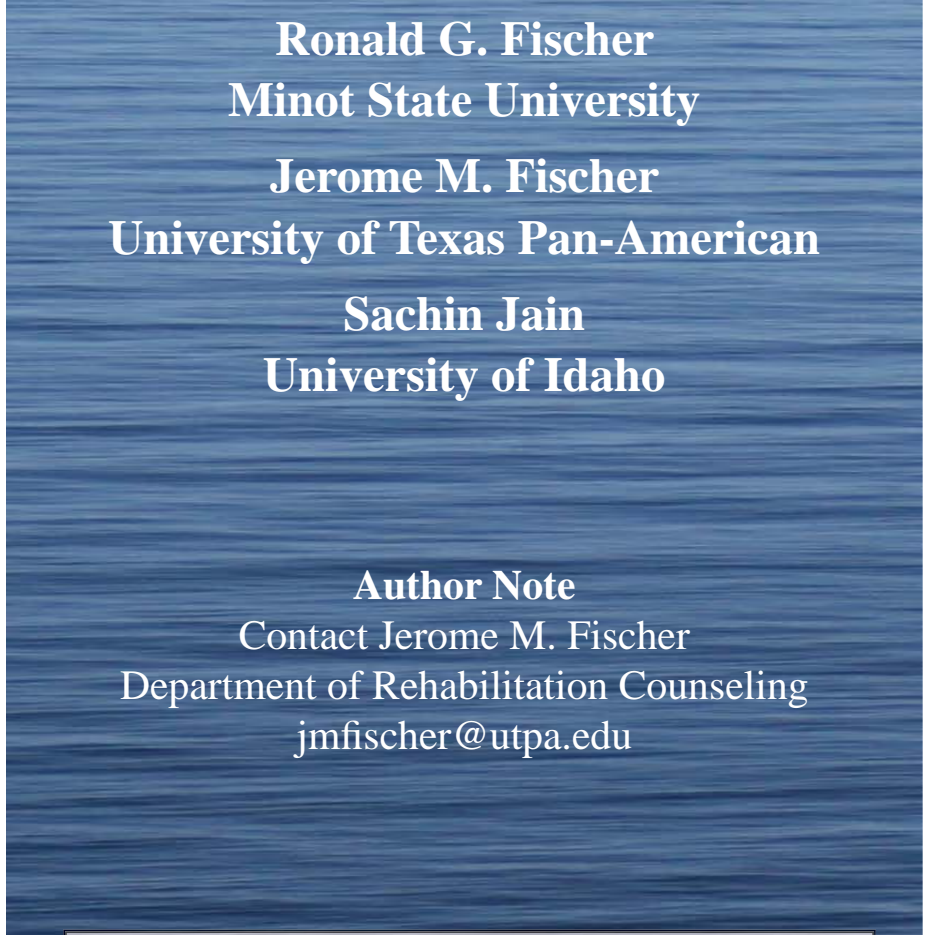

This study was designed to develop and initiate the validation of the Affective Cognition Writing Survey (ACWS), a psychological instrument used to measure emotional expression through writing. Procedures for development and validation of the instrument are reported. Subsequently, factor analysis extracted six factors: PositiveProcessing,LiberatingFeelings, Reader Consciousness, Conflict Processing, Inner Exploration, and Emotional Synthesis. The factors have important implications for counseling, conducting research sensitive to writing, emotional intelligence and education.

Key Words: expressive writing, emotional intelligence, affective counseling
It has been demonstrated that the disclosure of events and in particular traumatic events for most people is therapeutic (Frattaroli, 2006). Connecting emotions, language processing, and cognition (Pennebaker \& Francis, 1996) has led to research to determine the psychological effects of writing on emotions (Pennebaker, 1997). The act of writing has been associated with enhancing positive emotional processing and has been found to be therapeutic (Bootzin, 1997; Esterling, Abate, Murray, \& Pennebaker, 1999; Kloss, \& Lisman; 2002; Marlo,\& Wagner, 1999). Studies have provided evidence of the positive effects of writing on stress (Cameron \& Nicholls, 1998; Francis \& Pennebaker, 1992) trauma (Greenberg \& Stone; 1992; Park,\& Blumberg, 2002; Smyth, True \& Souto, 2001), intrusive thoughts and depression (Lepore, 1997), working memory (Klein \& Boals, 2001), and coping with job loss (Spera, Buhrfeind, \& Pennebaker, 1994). Furthermore, the processing of emotions to enhance the well being of individuals and clients has its roots in the emergence of the theoretical perspective of emotional intelligence.

\section{Expressive Writing Research Results}

The efficacy of disclosure and expressive writing has been researched (Frattaroli, 2006). However, the construct has been recognized to be complex (Smyth \& Pennebaker, 2008). Whereas therapeutic gain has been evidenced, some studies have had negative outcomes (Gidron, et al., 2002). Men with post traumatic stress disorder had increased illness-related doctor's visits. Some participants in disclosure research have found the experience to be counter-productive even objectionable (Frattaroli, 2001). Short-term increases in negative affect by focusing on stressful experiences have been reported, but long-term exacerbation of symptoms have been rare (Horowitz, 2008).

Other studies (Frisina, Borod, \& Lepore, 2004) found no significant increases in positive outcomes, e.g., participants with severe psychological issues (Bird, 1992), negative body image (Earnhardt, Martz, Ballard \& Curtin, 2002), primary insomnia (Mooney, Espie \& Broomfield, 2009) and suicidal tendencies (Kovac \& Range, 2002). Hence it has been posited that there may be different explanations for positive outcomes for expressive writing (Frattaroli, 2006). Smyth and Pennebaker (2008) suggested a cognitive-processing theory, whereby people who gain from writing about emotions try to make sense of the events they are disclosing, gain 
insight into the events, and organize and integrate the experiences into their self-schema. The aforementioned activities are related to emotional intelligence.

\section{Historical Emergence of Emotional Intelligence}

Traditionally intelligence has been measured by verbal, abstract, visual, and quantitative reasoning along with memory (Thorndike, Hagen, \& Sattler, 1986). Wechsler (1997) constructed his intelligence test to measure verbal and performance constructs. Subsequent factor analysis of the Wechsler IQ test identified verbal comprehension, perceptual organization, freedom from distraction and processing speed as underlying constructs (Kamphaus, Benson, Hutchinson, \& Platt, 1994). However, it has been recognized by the Wechsler that non-intellective factors need to be taken into account when assessing intelligence. These factors included inclination, affect, personality, drive, persistence, and goal awareness.

Howard Gardner (1983) conceived of intelligence as consisting of multiple abilities not typically measured by the various well-known intelligence tests. He posited that seven constructs existed: visual/spatial, musical, verbal, logical/mathematical, interpersonal, intrapersonal, and bodily/kinesthetic. Interpersonal intelligence was defined as communication and understanding others' feelings and motives. Accordingly, intrapersonal intelligence was defined as awareness of one's own feelings and self-motivation.

Since the 1990's emotional intelligence has become an emerging focal point for research (Davis, Stankov, \& Roberts, 1998; Elias, et al., 1997; Goleman, 1995; Mayer, Caruso, \& Salovey, 1999; Mayer \& Cobb, 2000; Mayer \& Salovey, 1993; Mayer \& Salovey, 1997). Emotional intelligence is made up of several factors. Salient among these factors is the ability to recognize the meaning of emotions. An individual who possesses a high Emotional Quotient (EQ) readily perceives emotions, assimilates emotion-related feelings, understands the information of those emotions, and manages them. Rather than suppressing emotional conflicts, a person with a high EQ can solve emotional problems. Doty (2001) expanded those attributes to include, handling stress, becoming less socially anxious and dealing with feelings of loneliness, gaining an ability to see and appreciate another's emotional state, and becoming empathetic, analyzing and understanding relationships, solving problems in relationships, understanding the emotional dynamics of groups, em- ploying group interaction skills, and managing the emotions of the group.

Research into emotional intelligence continues to grow and explore new dimensions. Emotional intelligence has been added to cognitive, social, psychological, and biological domains that influence learning (Taylor, Marienau, \& Fiddler, 2000). In education, by including emotional intelligence in the classroom, teachers and other educational professionals have improved student performance, especially those with learning disabilities (Pellitteri, Dealy, Fasano \& Kugler, 2006). Taylor's (2001) neurobiological research provided evidence that emotion highly influenced cognition. The research indicated that emotion filters information into relevant and irrelevant categories before cognitive operations are engaged which makes emotional intelligence an important factor in psychological processing. Consequently, the role of emotional intelligence in academic success has been researched (Bar-On, 2003; Parker et al., 2004; Parker, Summerfeldt, Hogan \& Majeski, 2004; Van der Zee, Thijs, \& Shakel, 2002).

Fischer and Fischer (2003) in their research provided evidence that emotional intelligence may be positively increased by an academic curriculum. The class consisted of readings of poems, short stories and plays, and viewing films. Through a series of classroom exercises including journaling, role plays, written assignments, and small group discussions, students were instructed in the exploring and understanding the emotional underpinnings of the literature.

Furthermore, they deconstructed the emotional dynamics and examined how the readings resonated with or were perhaps counterpoint to their own lives. Fischer and Fischer reported significant gains in emotional intelligence by a treatment group over and above a non-equivalent control group. The treatment group $(\mathrm{N}=13)$ with a mean age of $21.3(\mathrm{SD}=3.1)$ and range of 18 to 56 attended a freshman literature class, and the non-equivalent control group $(\mathrm{N}=15)$ with a mean age of $20.5(\mathrm{SD}=2.8)$ and range of 18 to 42 attended a freshman composition class. Both matriculated at a Midwestern University, and all were white. The treatment group attended a mean of $2.5(\mathrm{SD}=.7)$ college semester and the non-equivalent control group 1.8 (SD-.4). Positive significant differences were evident from pre- to post-test on an emotional intelligence 
measure (Jerebek, 2000) after students experienced a semester-long curriculum of reading and responding to literature designed to increase emotional intelligence. The changes recorded by the emotional intelligence self-report measure were congruent with the positive results of a pre- and post-test administration of a behavioral measure involving students responding in writing to an emotionally laden video.

\section{Increasing Emotional Intelligence}

Refining their research, Fischer and Fischer (2006) continued with development of the Affective Response to Literature Survey (ARLS) to capture a person's emotional intelligence more precisely as it pertains to literature. The ARLS measures students' receptive processing of emotions after reading, reflecting on, and analyzing literature. More specifically, the ARLS measured a person's ability to reflectively, synthesize emotions, act on emotions, process emotions, and respond in an emotionally empathetic way to literature. Validation procedures employed by Fischer and Fischer provided evidence of its sound psychometric properties.

Further validation of the ARLS was provided by the research of Chu (2005) who used the instrument to measure increased pre to posttest changes in a treatment group over a non-equivalent comparison group in a research project using quasi-experimental design. The treatment group consisted of participants $(\mathrm{N}=30)$ registered in the summer-session English reading class in 2004. They were sophomore, junior, and senior students in freshman English. Their ages ranged from 20 to 28 years $(M=22.4, S D=1.7)$. The non-equivalent control group consisted of participants $(\mathrm{N}=32)$ registered in another section of the summer-session English reading class in 2004. They were sophomore and junior students in freshman English. Their ages ranged from 18 to $35(\mathrm{M}=21.9, \mathrm{SD}=3.9)$.

Significant changes in ARLS scores were recorded by the treatment group. The non-equivalent comparison group had no significant changes. The research also reported significant positive findings when the ARLS was shown to have a strong correlation with a behavioral instrument also used to detect treatment group pre to posttest change.

The behavioral measure used was the Mental Ability Reading and Writing Quality Index (MARWQI) (Chu, 2005). It was designed by the researcher to measure participants' responses to a story in terms of emotional intelligence. The MARWQI was an ability test which is different from a self-report test. Participants engaged in expressive writing in response to a story, their behavioral responses were evaluated by two independent raters. Accordingly, the raters followed the directions of MARWQI rating responses on eight different items using a three-point Likert scale: 1 = Poor, 2 = Average, and 3 = Excellent. The eight items ranged from, "the story's emotional crises was recognized," to "the respondent self-disclosed his or her own emotional connections to the story." A numerical score was obtained measuring the participants' ability to perceive, understand, and manage their own emotional information and the story characters' emotions. The Spearman-Brown formula was used to compute reliability estimates of the average MARWQI ratings. A reliability coefficient of .64 was computed. Raters' scores were averaged to provide a single score for the behavioral ratings (Chu, 2005).

Although the work of Fischer and Fischer (2006, 2003) and Chu (2005) was significant, it was mainly focused on receptive and passive appraisal of emotional issues found in literature. Complementary research has been done to measure the effects of expressive writing on psychological processes and well-being (Marlo, \& Wagner, 1999). However, at present an instrument does not exist that could further expand the possibilities of emotional intelligence in this direction. An instrument is needed to specifically study the expressive dimension of emotional intelligence. Hence, researching emotional expression through writing would be a welcome new facet of emotional intelligence.

Research on emotional intelligence and, subsequently, the use of literature to enhance the emotional quotient was a significant contribution. To add to these branches of research this study investigated the development and initial validation of an instrument designed to measure people's emotional expression through writing. More specifically, the purpose of this study was to create a new psychological instrument, the Affective Cognition Writing Survey (ACWS). The research question of the study was as follows:

1. To what degree can a psychological measure of emotional expression of writing be validated?

\section{Method}

Participants. A total of 142 students at a large northwestern university enrolled in several composition classes participated in the study including 44 men (31\%) and 88 women (66\%) with 10 people not reporting gender. Selection of participants was based on con- 
venience. The participants had a mean age of 21.0 (SD $=6.6$ ) with a range of 17 to 53. Most students, 65\% (n =93), reported their class level as Freshman, 8\% ( $\mathrm{n}=$ 11) Sophomore, $6 \%(n=9)$ Junior, $8 \%(n=11)$ Senior, and $4 \%(n=5)$ Graduate Student, with $9 \%(n=13)$ not reporting. Most participants, $82 \%(n=117)$, reported they identified as being white, $1 \%(n=2)$ Latino, .7\% $(n=1)$ African American, 6\% $(n=8)$ identified themselves as international students. Note that $10 \%(n=14)$ did not report identifying with any cultural or ethnic group.

\section{Instrumentation}

Convergent Validity Instrument. The Affective Response to Literature Survey (ARLS) (Fischer \& Fischer, 2006) measure was used to provide evidence of a modest convergence with the Affective Cognition Writing Survey (ACWS) $(\mathrm{r}=.67, \mathrm{p}<.01)$. The ARLS measure was designed to measure a person's emotional responses to literature. The ARLS measure has been validated with excellent internal consistency (Cronbach's Alpha = .90) and high test-retest reliability ( $\mathrm{r}=$ .90 , p < .001). Additionally, the ARLS has demonstrated an ability to detect pre to posttest changes in a treatment group vs. a non-equivalent control group (Chu, 2005).

ACWS Item Development. A review of literature concerning emotional intelligence provided a wealth of information from which items concerning the expression of emotions through writing emerged (Davis, Stankov, \& Roberts, 1998; Fischer \& Fischer, 2006; Goleman, 1995; Jerabek, 2000; and Mayer, Caruso, \& Salovey, 1999). Subsequently, items were then formatted into a Likert type scale, where 1 = almost never; 2 = rarely; $3=$ sometimes; $4=$ often; and $5=$ most of the time.

Content Validity. Content validity for the ACWS was accomplished by employing the Content Validity Ratio process (Cohen, Swerdlik, \& Phillips, 1996). Initially, 25 items were developed for the Affective Cognitive Writing Survey and were rated for inclusion by 10 professionals, five with expertise in the field of psychology and the others in composition. The experts had a mean age of 51.7 years (SD $=7.8)$; $50 \%$ had a doctorate and the others a master's degree; $50 \%$ were female and 50\% male. The experts had a mean of 19.1 years (SD $=10.4$ ) working as professionals. The professionals reviewed each of the items using the follow- ing scale: 1 = essential, 2 = useful but not essential, and $3=$ not essential. The following formula was then used to compute the validity ratio:

$$
\frac{\mathrm{CVR}=\text { ne }-\mathrm{N} / 2}{\mathrm{~N} / 2}
$$

In this formula CVR = content validity ratio, ne = number of professionals indicating the items as "essential," and $\mathrm{N}=$ total number of professionals. For significance at the .05 level and inclusion in the ACWS, each item would have met the criteria of a CVR of .62 or higher (Cohen et. al, 1996). Of the original 25 items 22 were retained for inclusion in the ACWS after the expert validation process.

Readability. To determine the reading level of the ACWS, the Flesch-Kincaid Index (Flesch, 1974) was employed to give a statistical analysis of the difficulty of the text. The formula is $0.39 \mathrm{X}$ the average number of words in sentences $+11.8 \mathrm{X}$ the average number of syllables per word -15.59 . Readability was computed to be at the tenth grade level.

Procedures. The ACWS was posted in written form on a website at the beginning of the semester for students attending introductory composition classes at a large northwestern university. Students participated voluntarily and were given a number which they posted on the website to indicate they were part of the research group. The website was available for four weeks and then data was computed.

\section{Results}

\section{Psychometrics}

Means and standard deviations for the 22 items in the ACWS can be seen in Table 1.

Respondents rated as highest the two items \#8 I enjoy writing when I am expressing the things I care about $(\mathrm{M}=4.24, \mathrm{SD}=.84)$ and \#1 Writing lets me express my feelings $(\mathrm{M}=4.14$, SD = .89). Conversely, respondents rated as lowest the two items \#18 Writing helps me build relationships with others $(\mathrm{M}=2.78, \mathrm{SD}=$ 1.01) and \#19 I write with an audience in mind ( $\mathrm{M}=$ 3.33 , $\mathrm{SD}=1.06)$. The overall mean for the test was computed to be $81.6(\mathrm{SD}=11.3)$.

Reliability. The ACWS demonstrated high internal consistency (Cronbach's alpha $=.88$ ). Additionally, it demonstrated high test-retest reliability $(r=.90$, $\mathrm{p}<.001)$. 
Construct Validity. Convergent construct validity for the ACWS was demonstrated via correlations with relevant factors as seen in Table 2.

Significant correlations were reported that ranged from weak $(r=.21)$ to strongly moderate $(r=.67)$. Correlations were computed for the ACWS and the corresponding measures of the ARLS (Fischer \& Fischer, 2006), Interest in Writing About Emotions, Age, Frequency of Writing About Emotions in a Year. Nonsignificant correlations were reported for Frequency of Writing About Emotions in a Month and Frequency of Writing About Emotions in a Week.

In addition to the correlations, evidence of construct validity for the ACWS was provided in the study where it was used to detect treatment group change. The instrument measured pre to post-test differences in a treatment and non-equivalent comparison group design experiment. The treatment group was part of a semester long composition class specifically designed to increase emotional expression through writing.

The curriculum consisted of focused free writing exercises, journaling, four projects, and a research project which consisted of transforming one of four projects of narrative writing into expository writing. Table 3 contains an example of a focused free writing exercise and descriptions of the four writing projects.

Treatment group $(\mathrm{N}=15)$ pretest and posttest mean scores were compared using the Wilcoxson matchedpairs signed ranks test because of small sample size. Pretest scores $(\mathrm{M}=78.27, \mathrm{SD}=9.4)$ were significantly $(\mathrm{z}=3.18, \mathrm{p}, .001)$ lower than posttest scores $(\mathrm{M}$ $=86.46, \mathrm{SD}=7.9)$. The non-equivalent comparison group $(\mathrm{N}=13)$ pretest scores $(\mathrm{M}=84.29$, $\mathrm{SD}=8.47)$ were not significantly different $(\mathrm{z}=-1.35, \mathrm{p}>.05)$ than posttest scores $(\mathrm{M}=83.79$, SD 8.24). Finally, gain scores (posttest scores minus pretest scores) were compared between the treatment group $(\mathrm{N}=15)$ and the non-equivalent comparison group $(\mathrm{N}=13)$. Using the Mann Whitney $U$ for comparisons, the treatment group had significantly $(\mathrm{U}=-4.30, \mathrm{p}<.001)$ greater gain scores $(\mathrm{M}=7.81, \mathrm{SD}=6.61)$ than the non-equivalent comparison group ( $\mathrm{M}=-.50, \mathrm{SD} 1.29)$.

Lastly, a comparison between males and females using the ACWS reported results congruent with previous research in the field of emotional intelligence. Females scored significantly higher with an adjustment for unequal variances due to unequal sample sizes, t (108.81)

$$
\begin{aligned}
& =3.43, \mathrm{p}<.001,(\mathrm{M}=84.19, \mathrm{SD} 10.85) \text { than males }(\mathrm{M} \\
& =78.03, \mathrm{SD}=9.09) .
\end{aligned}
$$

Factor Analysis. Additional evidence of construct validity was provided by a varimax rotated factor analysis which was carried out to determine subscales within the ACWS (Huck, 2000). Six factors were extracted using principal component analysis as seen in Table 4.

The six factors accounted for $62.2 \%$ of the total variance. The first factor (items 2, 6, 7, 11, 12, 22) included items that involved emotional processing and was titled Positive Processing. The second factor (items 1, 3, 4, 8,10 ) included items that involved getting in touch with one's feelings and was titled Liberating Feelings. The third factor (items 19, 20, 21) included items that involved understanding one's audience and was titled Reader Consciousness. The fourth factor (items 13, $16,17)$ included items that involved merging emotions and logic was titled Conflict Processing. The fifth factor (items 5, 9, 18) included items that involved getting in touch with one's personal and relational dimensions and was titled Inner Exploration. Lastly, the sixth factor (items 14,15 ) included items that involved synergy and was titled Emotional Synthesis.

\section{Discussion}

In the past, research has narrowly focused on only a few dimensions of people's abilities. However, the constructs that have been identified as contributing to intellectual processes have continually expanded (Gardner, 1983). Moreover, social sciences have recently seen the emergence of more multi-dimensional theories which encompass emotional domains, as well as social, behavioral, and intellectual (Elksnin, \& Elksnin, 2003; Greenberg, Kusche, \& Riggs, 2004). This has led to studying the enhancement of emotional intelligence and, subsequently students' emotional response to literature as means of expanding the affective domain. The Affective Response to Literature Survey (ARLS) was a psychological measure developed and validated as a sensitive tool to more closely understand the emotional experiences of people in connection to literature. However, the instrument was limited to predominantly measuring a person's receptive emotional intelligence or, more specifically, the ability to synthesize, reflect on, process, and then act on affective responses to literature. The work of Pennebaker (1997) and others in the field have provided evidence that expressive writing is therapeutic and useful in alleviating distress. This lead to the development of the Affective Cognitive Writing 
Survey (ACWS) which is complimentary to the ARLS. The ACWS is an instrument designed to measure a person's emotional expression through writing.

This current research should be viewed within the context that it is an initial validation of the ACWS. More studies are encouraged to provide further validation of the measure. The people sampled in this study were predominantly young, women, and white, therefore, caution should be used when administering and interpreting the ACWS with other groups. On the other hand, the ACWS was developed through a rigorous process that assisted in the validation of its content and readabilty. Furthermore, the items that remained after the process proved to have excellent internal consistency and test/retest reliability.

\section{Limitations of the Study}

A significant limitation of this initial validation is that it did not control for the dispositional deficit in self-disclosure known as Alexythimia (Paez, Velasco, \& Gonzalez, 1999). Alexythimia is defined as a deficit in the cognitive processing and regulation of emotion. People with Alexythimia have the characteristics of difficulty in describing feelings to others, reduced capacity to engage in fantasy and other activities of the imagination, and a stimulus-bound, externally oriented cognitive style (Taylor, Bagby \& Parker, 1997). The presence of this deficit among participants may have affected the outcomes of this study. Future studies may investigate the relationship between Alexythimia and the ACWS using the Toronto Alexithymia Scale (TAS20) (Parker, Bagby, Taylor, Endler, \& Schmitz, 1993).

To determine the instrument's construct validity, its relationships with a number of factors were analyzed. The ACWS showed positive correlations with the ARLS, Interest in Writing About Emotions, Age, and Frequency of Writing About Emotions in a Year. Conversely, no correlations were found between the ACWS and Frequency of Writing About Emotions in a Month and Frequency of Writing About Emotions in a Week. The correlation between the ACWS and ARLS is important and shows that the ACWS is measuring a construct closely related to the emotional response to literature. However, the moderate correlation can be viewed as positive because this indicates it is also measuring something distinct. Accordingly, the moderate and weak correlations with Interest in Writing About Emotions and Frequency of Writing About Emotions respectively provide some validation if taken in concert.

Research has shown that age is an important factor in emotional experience as measured by the ARLS ( $\mathrm{r}=.24$, Table 2) (Aldwin, 1991; Barrick, Hutchinson, \& Deckers, 1989; Carstensen; 1995). The positive correlation with age found in this study supports past research and adds to the construct validity of the ACWS. Similarly, gender has been shown to be an important factor in the expression of emotion (Plant, Hyde, Keltner \& Devine, 2000; Vrana \& Rollock, 2002). Note that gender is not a factor in experiencing emotion-both genders tend to experience emotions congruently. However, it has been posited that perhaps due to socialization women express their emotions more readily. This research had similar findings with the females scoring 6 points higher than males on the ACWS.

Most importantly the ACWS was able to detect the increase of scores of students involved in a semester long writing curriculum centered on developing emotional expression through writing. Also validating the instrument's usefulness, the non-equivalent comparison group who were not engaged in an emotional expression writing curriculum reported no significant differences in their pre to posttest scores.

Understanding the interplay between emotional intelligence and multidimensional psychological processes will be enhanced by the development of the ACWS. It is recognized that the work of the current investigation, although significant, is a beginning. Accordingly, further research using the ACWS should also provide more depth of understanding of the influences of gender, age, culture and personality upon the emotional expression of writing.

\section{Implications of Subscales}

The six subscales Positive Processing, Liberating Feelings, Reader Consciousness, Conflict Processing, Inner Exploration, and Emotional Synthesis have the potential to facilitate a more refined exploration of the psychological process of clients. Moreover, the scales might assist a counselor in opening topics with a client. The scores could be reviewed with the client and then related to the client's perceptions of communication of their world view, their getting in touch with feelings, their understanding of the constraints of their perspective, the integration of their perspectives with others and their making meaning of their experiences. These 
subscales have relevance to the theory of cognitiveprocessing (Smyth \& Pennebaker, 2008) that has been suggested as an explanation for why some people benefit from disclosure. It has been posited that expressive writing assists people who have experienced traumatic events by making sense of the event (Positive Processing and Liberating Feelings), gaining insight into the event, (Conflict Processing and Inner Exploration), and organizing and integrating distressing experiences into one's self-schema (Emotional Synthesis).

Identifying the six factors has important implications for conducting more sensitive research concerning writing and enhancing emotional intelligence. Accordingly, the ACWS may be useful for working with college students who have been sent to a college counseling center who have been involved in disputes or other interpersonal conflicts. For example, a counselor administers the ACWS to a group of freshman students at the initial contact and determines that the students on average score 2.0 (average being 2.5 on a 5 point scale) on the subfactor Conflict Processing. To determine if this attribute can be improved, the counselor implements a 4 to 6 week writing assignment. The counselor has the students develop 4 or 5 topics that involve their conflict experiences. They discuss the topics in group and then are asked to choose one topic and write their thoughts and feelings, describe the moments of the experience, put down the sensory experiences at the time what they heard, smelled, felt, tasted, and the way things looked. They write what they thought at the time and what they think now as they look back. Lastly, the counselor has the class write dialogue from the moments. They write from the voice of each person in the moment, getting in touch with each person's emotions and cognitions. Group discussions are held with each student reading their story and then the stories are role played.

Understanding psychological process through the emotional expression in writing has many exciting possibilities. Intrapersonal, interpersonal, and cultural emotional issues create difficult conflicts for people. These may be alleviated to some degree by people writing about their experiences. The ACWS may help readers to more fully understand themselves and give direction for them to enhance their personal growth in this area of study.

\section{Conclusions}

Through a rigorous process, research has found the ACWS to be a viable instrument, but recognizes that it needs further evidence of its validity. It can be concluded that it has substantial psychometric properties of reliability and validity. It may be used for a more sensitive exploration of use of the emotional expression of writing.

Recommendations are for further research using the ACWS. The present study had a relatively small sample size without a sufficient range of diversity represented, in particular men. Additional research could be done using a variety of populations with greater numbers and incorporate the Toronto Alexithymia Scale (TAS-20). As presented in this study, the ACWS is a complimen tary measure to the ARLS; the former being expressive and the latter more receptive. Further research might use both measures to evaluate a greater range of individual responses both to literature and expressive writing in counseling. 


\section{References}

Aldwin, C. M. (1991). Does age affect the stress and coping process? Implications of age differences in perceived control. Journal of Gerontology: Psychological Sciences, 46, 174-180.

Barrick, A. L., Hutchinson, R. L., \& Deckers, L. H. (1989). Age effects on positive and negative emotions. Journal of Social Behavior and Personality, 4, 421-429.

Bar-On, R. (2003). How important is it to educate people to be emotionally and socially intelligent, and can it be done? Perspectives in Education, 21, 3-13.

Bird, G. (1992). Programmed writing as a method for increasing self-esteem, self-disclosure and coping skills. (Doctoral dissertation, Georgia State University, 1992). Dissertation Abstracts International, 53, 2536.

Bootzin, R. (1997). Examining the theory and clinical utility of writing about emotional experiences. Psychological Science, 8, 167-169.

Cameron, L. \& Nicholls, G. (1998). Expression of stressful experiences through writing: Effects of a self-regulation manipulation for pessimists and optimists. Health Psychology, 17, 84-92.

Carstensen, L. L. (1995). Evidence for a life-span theory of socioemotonal selectivity. Current Directions in Psychological Science, 4, 151-156.

Chu, Y. (2005). Celebrating Self-Actualization: Improving emotional intelligence through a cognitive-based English reading curriculum. Unpublished doctoral dissertation. University of Idaho, Moscow, Idaho.

Cohen, R. J., Swerdlik, M. E., \& Phillips, S. M. (1996). Psychological testing and assessment. Mountain View, CA: Mayfield Publishing Company.

Davis, M., Stankov, L., \& Roberts, R. D. (1998). Emotional intelligence: In search of an elusive construct. Journal of Personality \& Social Psychology, 75, 989-1015.

Doty, G. (2001). Fostering emotional intelligence in K-8students. Thousand Oaks, CA: Corwin Press Inc.

Earnhardt, J., Martz, D., Ballard, M., \& Curtin, L. (2002). A writing intervention for negative body image: Pennebaker fails to surpass the placebo. Journal of College Student Psychotherapy, 17, 19-35.

Elksnin, L. K. \& Elksnin, N. (2003). Fostering social-emotional learning in the classroom. Education, 124, 6375.

Esterling, B. A., Abate, L., Murray, E., \& Pennebaker, J. (1999). Empirical foundations for writing in prevention and psychotherapy: Mental and physical health outcomes. Clinical Psychology Review, 19, 79-96.

Fischer, R.G., \& Fischer, J. M. (2006). The development of an emotional response to literature measure: The affective response to literature survey. Alberta Journal of Educational Research, 52, 265-276.

Fischer, R. G. \& Fischer, J. M. (2003). The development, testing, and evaluation of an emotional intelligence curriculum. MPAEA Journal of Adult Education, 32(1), 7-17.

Flesch, R. F. (1974). The art of readable writing. NY, NY: Harper Collins.

Francis, M. E. \& Pennebaker, J. (1992). Putting stress into words: The impact of writing on physiological, absentee, and self-reported emotional well-being measures. American Journal of Health Promotion, 6(4), 280-287.

Frattaroli, J. (2001). Topic switching in expressive writing. Unpublished raw data. 


\section{References}

Frattaroli, J. (2006). Experimental disclosure and it moderators: A meta-analysis. Psychological Bulletin, 132(6), 823-865.

Frisina, P., Borod, J., \& Lepore, S. (2004). A meta-analysis of the effects of written emotional disclosure on the health outcomes in clinical populations. Journal of Nervous and Mental Disease, 192, 629-634.

Gardner, H. (1983). Frames of mind: The theory of multiple intelligences. New York: Basic.

Gidron, Y., Duncan, E., Laza, A., Biderman, A., Tandeter, H., \& Shvartzman, P. (2002). Effects of guided written disclosure of stressful experiences on clinic visits and symptoms in frequent clinic attenders. Family Practice, 19, 161-166.

Goleman, D. (1995). Emotional intelligence. New York: Bantam.

Greenberg, M. T., Kusche, C. A., \& Riggs, N. (2004). The PATHS curriculum: Theory and research on neurocognitive development and school success. In J.E. Zins, Weissberg, R. P., Wang, M.C. \& Walberg, H.J. (Ed.), Building academic success on social and emotional learning: What does the research say? New York: Teachers College Press.

Greenberg, M. A., \& Stone, A. A. 1992). Writing about disclosed versus undisclosed traumas: Immediate and long-term effects on mood and health. Journal of Personality and Social Psychology, 62, 75-84.

Horowitz, S. (2008). Evidence-based health outcomes of expressive writing. Alternative and Complementary Therapies, 14(4), 194-198.

Huck, S. (2000). Reading statistics and research (3rd ed.). New York, NY: Addison Wesley Longman.

Jerabek, I. (2000). Emotional intelligence. http://www psych tests.com/tests/iq/emotional_iq_r2_accessl.html.

Kamphaus, R. W., Benson, J., Hutchinson, S., \& Platt, L. O. (1994). Identification of factor models for the WISCIII. Educational and Psychological Measurement, 54, 174-186.

Klein, K., \& Boals, A. (2001). Expressive writing can increase working memory capacity. Journal of Experimental Psychology: General, 130, 520-533.

Kloss, J. D., \& Lisman, S. A. (2002). An exposure-based examination of the effects of written emotional disclosure. British Journal of Health Psychology, 7, 31-46.

Kovac, S. \& Range, L. (2002). Writing projects: Lessening undergraduates’ unique suicidal bereavement. Suicide and Life-Threatening Behavior, 30, 50-60.

Lepore, S.J. (1997). Expressive writing moderates the relation between intrusive thoughts and depressive symptoms. Journal of Personality and Social Psychology, 73, 1030-1037.

Marlo, H., \& Wagner, M. K. (1999). Expression of netative and positive events through writing: Implications for psychotherapy and health. Psychology and Health, 14, 193-215.

Mayer, J. D., Caruso, D. R., Salovey, P. (1999). Emotional intelligence meets standards for traditional intelligence. Intelligence, 27, 267-298.

Mayer, J. D., \& Cobb, C. D. (2000). Education policy on emotional intelligence: Does it make sense? Educational Psychology Review, 12(2), 163-183. 


\section{References}

Mayer, J. D., \& Salovey, P. (1993). The intelligence of emotional intelligence. Intelligence, 12(4), 433-442.

Mayer, J. D., \& Salovey, P. (1997). What is emotional intelligence? In P. Salovey* D. Sluyter (Eds.). Emotional development and emotional intelligence: Implications for educators (pp.3-31). New York: BasicBooks.

Mooney, P., Espie, C., \& Broomfield, N. (2009). An experimental assessment of a Pennebaker writing intervention in primary insomnia. Behavioral Sleep Medicine, 7, 99-105

Murray, E. J., \& Segal, D. L. (1994). Emotional processing in vocal and written expression of feelings about traumatic experiences. Journal of Traumatic Stress, 7, 391-405.

Park, C., \& Blumberg, C. (2002). Disclosing trauma through writing: Testing the meaning-making hypothesis. Cognitive Therapy and Research, 26, 597-616.

Parker, J. Bagby, R. Taylor, G., Enler, N., \& Schmitz, P. (1993). Factorial validity of the 20-item Toronto Alexythimia Scale. European Journal of Personality, 7, 221-232.

Parker, J. D. A., Creque, R. E., Barnhart, D. L., Harris, J. I., Majeski, S. A., Wood, L. M., Bond, B. J., \& Hogan, M. J. (2004). Academic achievement in high school: Does emotional intelligence matter? Personality and Individual Difference, 37, 1321-1330.

Parker, J. D. A., Summerfeldt, L. J., Hogan, M. J., \& Majeski, S. A. (2004) Emotional intelligence and academic success: Examining the transition from high school to university. Personality and Individual Differences, 36 , 163-172.

Paez, D., Velasco, C., \& Gonzalez, J. (1999). Expressive writing and the role of alexythimia as a dispositional deficit in self-disclosure and psychological health. Journal of Personality and Social Psychology, 77(3), 630641.

Pellitteri, J., Dealy, M., Fasano. C. \& Kugler, J. (2006). Emotionally intelligent interventions for students with reading disabilities. Reading \& Writing Quarterly, 22, 155-171.

Pennebaker, J. (1997). Writing about emotional experiences as a therapeutic process. Psychological Science, 8, 162-166.

Pennebaker, J., \& Francis, M. (1996). Cognitive, emotional, and language process in disclosure. Cognition and Emotion, 10, 601-626.

Plant, E.A., Hyde, J.S., Kelner, D., \& Devine, P.G. (2000). The gender stereotyping of emotions. Psychology of Women Quarterly, 24, 81-92.

Smyth, J.M., \& Pennebaker, J.W. (2008). Exploring the boundary conditions of expressive writing: In search of the right recipe. British Journal of Health Psychology, 13, 1-7.

Smyth, J.M., True, N., \& Souto, J. (2001). Effects of writing about traumatic experiences: The necessity for narrative structuring. Journal of Social and Clinical Psychology, 20, 161-172.

Spera, S.P., Buhrfeind, E.D., \& Pennebaker, J.W. (1994). Expressive writing and coping with job loss. Academy of Management Journal, 37, 722-733.

Taylor, E. W. (2001). Transformative learning theory: a neurobiological perspective of the role of emotions and unconscious ways of knowing. International Journal of Lifelong Education, 20(3), 218-236. 


\section{References}

Taylor, G., Bagby, R. \& Parker, J. (1997). Disorders of affect regulation: Alexithymia in medical and psychiatric illness. Cambridge, England: Cambridge University Press.

Taylor, K., Marienau, C., \& Fiddler, M. (2000). Developing adult learners: Strategies for teachers and trainers. San Francisco: Josey-Bass.

Thorndike, R. L., Hagen, E. P., \& Sattler, J. P. (1986). Technical manual for the Stanford-Binet Intelligence Scale, Fourth Edition. Chicago: Riverside.

Van der Zee, K., Thijs, M., \& Schakel, L. (2002). The relationship of emotional intelligence with academic intelligence and the Big Five. European Journal of Personality, 16, 1003-1025.

Vrana, S. R., \& Rollock, D. (2002). The role of ethnicity, gender, emotional content, and contextual differences in physiological, expressive, and self-reported emotional responses to imagery. Cognition and emotion, 16, 165-192.

Wechsler, D. (1997). Wechsler Adult Intelligence Scale-Third Edition. San Antonio: The Psychological Corporation. 


\section{Appendix}

Table 1

Means and Standard Deviations for ACWS Items

\begin{tabular}{|c|c|c|}
\hline Item & Mean & $\begin{array}{l}\text { Standard } \\
\text { Deviation }\end{array}$ \\
\hline 1. Writing lets me express my feelings & 4.15 & .89 \\
\hline $\begin{array}{l}\text { 2. Writing gives me a clearer understanding of the feelings I } \\
\text { am having }\end{array}$ & 3.73 & 1.04 \\
\hline $\begin{array}{l}\text { 3. I tend to use a specific form of writing to express my } \\
\text { emotions (i.e., a journal, or poetry or e-mails, or letters, or a } \\
\text { diary, etc.) }\end{array}$ & 3.55 & 1.12 \\
\hline 4. Writing allows me to share my feelings with others. & 3.69 & 1.16 \\
\hline $\begin{array}{l}\text { 5. I include personal experiences that I feel are important in } \\
\text { my writing. }\end{array}$ & 4.10 & .72 \\
\hline 6. Writing helps me process my feelings. & 3.82 & .99 \\
\hline 7. I usually enjoy my writing experiences. & 3.46 & 1.00 \\
\hline $\begin{array}{l}\text { 8. I enjoy writing when I am expressing the things I care } \\
\text { about. }\end{array}$ & 4.24 & .84 \\
\hline $\begin{array}{l}\text { 9. I enjoy writing when I am exploring the things related to } \\
\text { my life. }\end{array}$ & 4.03 & .85 \\
\hline $\begin{array}{l}\text { 10. I try to find a way to feel some satisfaction even when } \\
\text { the writing project has little appeal to me }\end{array}$ & 3.54 & 1.08 \\
\hline $\begin{array}{l}\text { 11. I enjoy writing because of the insights that come to me } \\
\text { while I am writing. }\end{array}$ & 3.57 & 1.08 \\
\hline 12. I usually feel pleased when I complete a writing project. & 3.81 & 1.02 \\
\hline $\begin{array}{l}\text { 13. When writing, I try to use both emotional appeals and } \\
\text { logical reasoning to make my points. }\end{array}$ & 3.90 & .79 \\
\hline $\begin{array}{l}\text { 14. The success of my writing depends upon the emotional } \\
\text { energy I bring to it. }\end{array}$ & 3.99 & .86 \\
\hline $\begin{array}{l}\text { 15. When writing, I allow myself the freedom to contradict } \\
\text { myself. }\end{array}$ & 3.70 & .91 \\
\hline $\begin{array}{l}\text { 16. In my writing, I mention my doubts by stating the things } \\
\text { I have questions but no answers for. }\end{array}$ & 3.70 & .94 \\
\hline $\begin{array}{l}\text { 17. I can risk writing things I have doubts about because I } \\
\text { can always make qualifying explanations on those views as } \\
\text { I write. }\end{array}$ & 3.56 & .89 \\
\hline 18. Writing helps me build relationships with others & 2.78 & 1.01 \\
\hline 19. I write with an audience in mind & 3.33 & 1.06 \\
\hline 20. I imagine how a reader will respond to my writing & 3.54 & 1.03 \\
\hline $\begin{array}{l}\text { 21. I re-write or re-word things that will likely offend my } \\
\text { reader so they come out less offensive. }\end{array}$ & 3.46 & 1.02 \\
\hline $\begin{array}{l}\text { 22. When making strong points, I purposely write in a way } \\
\text { that holds my reader's attention long enough to read all of } \\
\text { what I have to say. }\end{array}$ & 3.85 & .70 \\
\hline
\end{tabular}




\section{Appendix}

Table 2

Correlations of Relevant Measures and Factors

\begin{tabular}{|c|c|c|c|c|c|c|c|}
\hline \multicolumn{8}{|c|}{ Measure $^{1}$} \\
\hline Measure $^{1}$ & 1 & 2 & 3 & 4 & 5 & 6 & 7 \\
\hline 1 & - & $.67 * *$ & $.58 * *$ & $.24 * *$ & $.21 *$ & .14 & .10 \\
\hline 2 & & - & $.61 * *$ & $.26 * *$ & $.17^{*}$ & .11 & $.19^{*}$ \\
\hline 3 & & & - & $.18^{*}$ & $.29 * *$ & $.26^{* *}$ & $.30 * *$ \\
\hline 4 & & & & - & .14 & .07 & .16 \\
\hline 5 & & & & & - & $.66^{* *}$ & $.55^{* *}$ \\
\hline 6 & & & & & & - & $.70 * *$ \\
\hline 7 & & & & & & & - \\
\hline
\end{tabular}

Measure $^{1} 1=$ ACWS, $2=$ ARLS, $3=$ Interest in Writing About Emotions, $4=$ Age, $5=$ Frequency of Writing About Emotions in a Year, $6=$ Frequency of Writing About Emotions in a Month, 7 =/Frequency of Writing About Emotions a Week 


\section{Appendix}

Table 3

Focused Free Write Exercise and Four Writing Projects

\section{Beginnings}

Pick a moment in your life, a first, the first time you went to school—first grade, middle school, high school, college - the first time you drove a car, got a job, got kissed, played a recital, got a paycheck, lived alone, fell in love, or broke up with someone, put your pet to sleep, made an important decision on your own. Find the most significant moment in that story and put us there. Put down what people said. Write what happened. Let us be in that scene with everything that was there-the sounds, smells, tastes, sights, textures, of things. Put the thoughts down that went through your mind then. Tell us what you were thinking and feeling then, and what you think and feel about this event now.

○ Writing about Others - the wounds someone carries, the absurdities or joys that a person has experienced, or the passions for something

○ Writing about Self - the wounds you carry, the absurdities or joys you have experienced, or the passions you have for something

- Writing for Social Change-what you see at work or school, at any service agency (doctor, dentist, hospital, government office) or concern (church, business, social group), with any behavior or method, with anything that you see is wrong and know that something has to change, something has to be done to fix it

- Writing about Your Writing — reflections about yourself as a writer drawn from your history of writing experiences, from different kinds of writing you have done (notes, e-mails, poems, journals, diaries, essays), from the journal you kept about the writing you have done this semester, from the comments you received about your writing 


\section{Appendix}

Table 4

Factor Analysis of the ACWS

\begin{tabular}{|c|c|c|c|c|c|c|}
\hline \multirow{2}{*}{$\frac{\text { Items }}{\text { ACWS }}$} & \multicolumn{6}{|c|}{ Principle Components } \\
\hline & 1 & 2 & 3 & 4 & 5 & 6 \\
\hline 1 & .53 & .58 & -.09 & .03 & .23 & .04 \\
\hline 2 & .70 & .25 & .14 & .14 & .24 & .13 \\
\hline 3 & .06 & .81 & .04 & -.13 & .11 & .06 \\
\hline 4 & .22 & .67 & .13 & .29 & .22 & .03 \\
\hline 5 & .08 & .04 & .11 & .33 & .55 & .15 \\
\hline 6 & .70 & .22 & .06 & .23 & .25 & .03 \\
\hline 7 & .60 & .48 & .08 & -.04 & .22 & .20 \\
\hline 8 & .41 & .47 & .07 & .22 & .41 & .03 \\
\hline 9 & .47 & .29 & .07 & .26 & .53 & -.05 \\
\hline 10 & .22 & .53 & .27 & .40 & -.24 & .08 \\
\hline 11 & .54 & .45 & -.08 & .15 & .18 & .03 \\
\hline 12 & .72 & -.05 & .02 & .17 & -.06 & .07 \\
\hline 13 & .31 & .26 & .31 & .49 & -.25 & -.01 \\
\hline 14 & .10 & .18 & .05 & .21 & -.07 & .73 \\
\hline 15 & .11 & -.07 & .14 & .09 & .17 & .81 \\
\hline 16 & .09 & .06 & -.05 & .77 & .09 & .12 \\
\hline 17 & .13 & -.01 & .03 & .70 & .19 & .17 \\
\hline 18 & .22 & .23 & .05 & -.06 & .58 & .09 \\
\hline 19 & -.09 & .19 & .76 & -.12 & .35 & .02 \\
\hline 20 & .22 & -.05 & .78 & .06 & .12 & -.01 \\
\hline 21 & .05 & .04 & .69 & .10 & -.18 & .15 \\
\hline 22 & .60 & .14 & .35 & -.06 & .03 & .27 \\
\hline
\end{tabular}

